\title{
ACHIEVEMENTS OF THE INTERNATIONAL GEOLOGICAL CORRELATION PROGRAMME AS RELATED TO HUMAN NEEDS
}

by

John A. Reinemund and Janet V. Watson

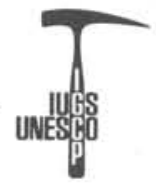

This abridged version of a report prepared by two IGCP Board members summarizes in a non-technical manner the achievements of the Programme to date. The report evaluates the effectiveness of IGCP insofar as human needs are concerned. Approved by the IGCP Board at its sixth session in February, the report will be presented to the UNESCO General Conference in October.*

A cooperative enterprise organised by the International Union of Geological Sciences (IUGS) and United Nations Educational, Scientific and Cultural Organization (UNESCO), the International Geological Correlation Programme (IGCP) is designed to encourage international research on geological problems related to identifying and assessing natural resources and improving man's environment. It is an outgrowth of a proposal first formulated in 1967 by representatives of IUGS and UNESCO, who recognized the need for a more concerted international effort to solve some fundamental geological problems.

Since its formal inception in 1973, IGCP has increased dramatically in size and scope. By the end of 1977 the Programme included 62 projects involving more than 1,000 geologists in 56 countries. Moreover, 102 countries have indicated an interest in the Programme by establishing national committees or contact offices for IGCP. This growth has been achieved with a modest investment of UNESCO funds, averaging about $\$ 100,000$ per year. At least 50 times this amount is now being spent annually by participating institutions and governments on scientific work directly related to IGCP projects, and the data being used on these projects, much of which comes from other programmes, probably represents an investment at least 100 times the UNESCO funding.

Because the Programme is a unique effort in coordinating the interests of a non-governmental scientific union and an inter-governmental organization, and because the operating procedures of IGCP have not previously been used by an international programme, IGCP's effectiveness in achieving its designated goals is of great concern to both IUGS and UNESCO.

\section{IGCP ROLE AND SIGNIFICANCE}

\section{International scope of geological research}

IGCP helps to fill a long-recognized need for a more effective instrument to mobilize worldwide geological expertise in the study of geological phenomena that transcend national boundaries. It is a significant extension of the activities of the International Geological Congress and IUGS. The Congress has been among the most active forces for worldwide geological contacts and exchange of information. IUGS, which has its roots in the Congress and was organized in 1961, is one of the largest and most active scientific unions, with 83 member countries, 43 commissions or committees, and 14 affiliated international associations. In the light of this long history of international exchange, it is not surprising that the world's geologists have taken the initiative, through IUGS, to establish this unique mechanism of cooperation jointly with UNESCO.

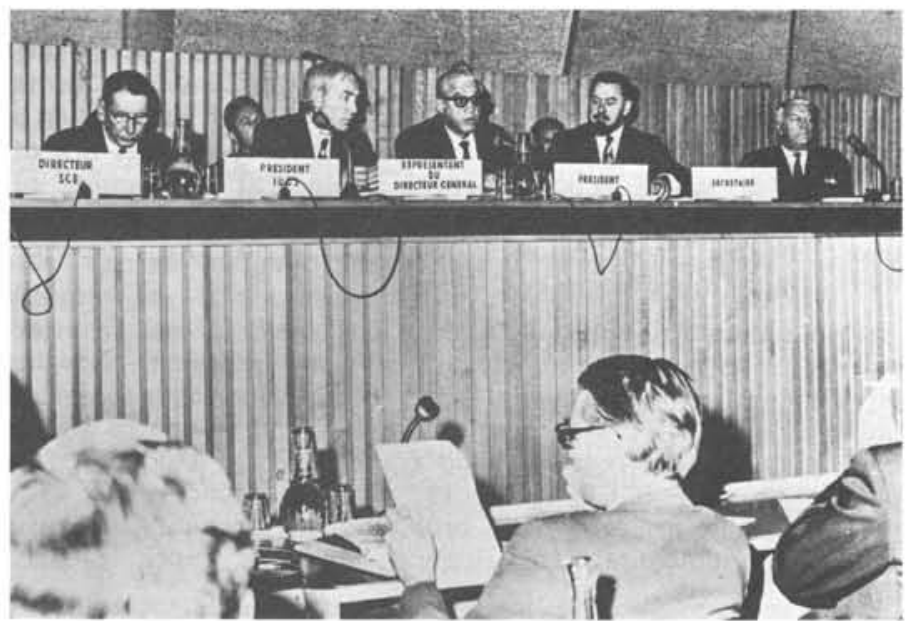

An inter-governmental conference of experts was called in 1971 in Paris to prepare for an International Geological Correlation Programme. Left to right: Sir Kingsley Dunham (U.K. - then President of IUGS), M. Batisse (France UNESCO), G.P. Salas (Mexico - President of the conference and currently a Vice-President of IUGS), F. Ronner (AustriaSecretary of the conference, now Director of the Geological Survey of Austria), W.P. van Leckwijk (Belgium - conference rapporteur and a former Secretary General of IUGS).

\footnotetext{
*EDITOR'S NOTE: The IGCP Board at its fifth session in 1977 decided to appraise the Programme as a whole, since it had been in operation for five years. Project Leaders were asked to submit reports of approximately 2,500 words in length reviewing the scientific progress of their projects and evaluating the significance of the achievements, particularly in terms of cooperation and communication between scientists from different regions, the extent of transfer of knowledge to developing countries, and developments in international standards and terminology. Their reports are currently being prepared for publication by UNESCO on behalf of IGCP by Dr. M.G. Bassett (Chairman, IUGS Advisory Board for Publication). Professor J.V. Watson and Dr. J.A. Reinemund accepted the task of preparing a short "general interest" document for the parent organizations of IGCP, that is, IUGS and UNESCO, summarizing the contents of the Project Leaders' assessments. Their report will form the introduction to the compendium volume to be published by UNESCO, and will be included in full in IGCP's Geological Correlation, No. 6, later this summer. (A list of IGCP projects is available, on request, from the IUGS Secretariat.)
} 
The activities of the commissions, committees, and affiliated organizations of IUGS focus on the stimulation of scientific investigations, standardization of methods and terminology, and exchange of information in all aspects of geology. They are not only essential for worldwide advancement of the science, but also form the necessary basis for identifying, defining, and establishing most of the IGCP projects.

The International Union of Geodesy and Geophysics (IUGG) also has many activities relevant to IGCP. Of special importance is the Geodynamics project (ICG) sponsored jointly by IUGG, IUGS and ICSU.

Among the inter-governmental mechanisms which provide research results that contribute toward the objectives and activities of IGCP are such scientific programmes as the International Decade of Ocean Exploration, the International Programme of Ocean Drilling, and the International Hydrological Programme. Resource programmes such as the United Nations Development Programme (UNDP), International Atomic Energy Agency (IAEA), and United Nations Revolving Fund (UNRF) can make use of the results of IGCP research.

\section{Geological contributions to human needs}

From an inter-governmental viewpoint, international cooperation in geological research is important as a means of helping solve economic and social problems. In his opening remarks to the first session of the IGCP Board in May 1973, the Deputy Director-General of UNESCO referred to the need for IGCP attention to the growing shortages of energy and mineral raw materials, resulting in slower economic growth in the developing countries and generally reduced living standards for mankind. The President of IUGS commented on the social climate and environmental concerns, especially in the developing countries: the effects of growing water shortages, desertification, environmental contamination, and the geological hazards which have taken a heavy toll in lives and property. All these problems are of regional or world scope, involve geological phenomena of international dimensions, require coordinated attention of geoscientists from many countries, and are growing increasingly more acute each year.

At present, about $45 \%$ of IGCP projects are oriented toward solving problems concerned with resources and the environment; the rest deal with correlation of geological units or events, or with new techniques and standards which can be helpful in resource and environmental studies. The proportion of IGCP projects directly concerned with resources and environmental problems will probably increase as their geological significance becomes more clearly defined.

\section{Unique role of IGCP}

IGCP combines the advantages of objective, nongovernmental scientific participation and guidance through IUGS with the benefits of inter-governmental support through UNESCO. It draws on the results of all relevant programmes, and in turn contributes research results that can strengthen them. But its main source of strength lies in the support it has received from geologists around the world. Most of the personnel and financial commitments to IGCP projects have been arranged through the efforts of the participating scientists themselves, with relatively less formal support from governments.

\section{GOALS AND MECHANISMS}

\section{Definable programme and project goals}

In 1971 a UNESCO Inter-governmental Conference of Experts defined the major aims and objectives for the Programme:
1. To obtain answers to interrelated theoretical and practical geological problems through international cooperation.

2. To support and strengthen existing geological correlation activities and to tackle those problems which cannot be solved under existing frameworks.

Major problem and research areas were identified as:

a. Shortage of energy and mineral resources: the need for better geological knowledge and methods for finding and evaluating resources.

b. Environmental conditions affecting urban and rural development: the need for better knowledge of geological events and processes that affect human activity and use of the environment.

c. Regional and intercontinental correlations: the need for a better understanding of natural processes, rock correlations, and geological events as a background for solving resource and environmental problems.

d. Standards and methods: the need for better standards of classification, terminology, and procedure in geological research, and for development and application of new methods of correlation.

In developing IGCP, efforts have been made to achieve a balanced effort in these four areas, to accustom project leaders and participating scientists to the necessary procedures for conducting and reporting their activities in accordance with IGCP aims, and to stimulate and initiate research on those problems that need attention most urgently.

\section{Mechanisms for achieving goals}

The operating mechanisms within IGCP have had a relatively short time to function. Development and management of the Programme are the responsibility of the IGCP Board, which is well balanced both geographically and

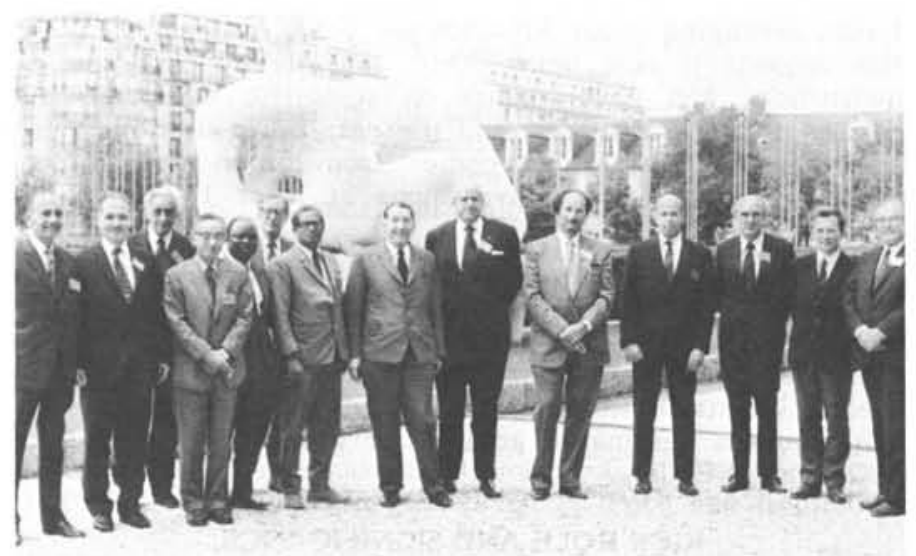

Attending the first IGCP Board meeting in Paris, 1973, left to right: R. Said (Egypt), F. Kabbani (Saudi Arabia), J. Marçais (France), C. Nishiwaki (Japan), M.O. Oyawoye (Nigeria), D.J. McLaren (Canada-currently Chairman of the Board), M.K. Roy Chowdhury (India), Sir Kingsley Dunham (U.K. then Chairman of the Board), G.P. Salas (Mexico), H.K. Erben (Federal Republic of Germany), J.A. Reinemund (U.S.A. - one of the co-authors of this report), J.J. Bigarella (Brazil), J. Petranek (Czechoslovakia), and M.F. Glaessner (Australia). (Not present were Academician V.V. Menner, U.S.S.R., and the two ex-officio members, E.M. Fournier d'Albe, UNESCO and S. van der Heide, Secretary General, IUGS). 
scientifically. The Board draws on the evaluations and recommendations of the Scientific Committees. Project proposals have been submitted by individual scientists mostly through IGCP National Committees in participating countries, or through IUGS.

Unfortunately, until recently relatively few National Committees were established and functioning adequately to fulfill their vital role in the Programme, which is to stimulate and approve proposals that would meet IGCP objectives and to encourage participation in those projects that are most important from a national viewpoint. Thus the scope and balance of the Programme to date have been determined largely by individual initiatives, although some of the newer projects are results of the Board's efforts to identify gaps in research and to stimulate proposals to fill them.

\section{Organization of IGCP within framework of parent} international scientific bodies

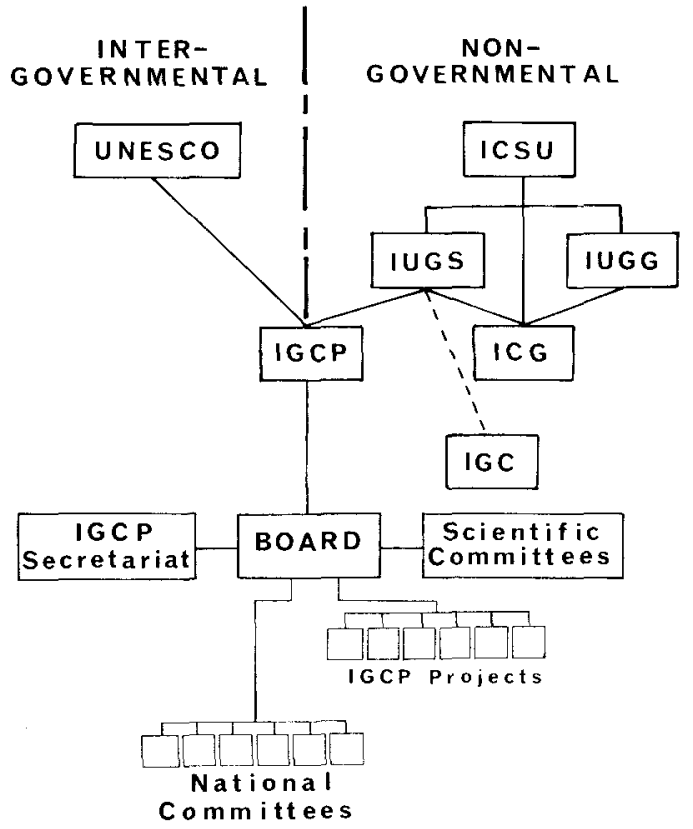

\section{Measuring progress and achievements}

The achievements of IGCP have been classified, reviewed, and evaluated in relation to the principal aims and objectives outlined above. Scientific achievements were considered in the context of the four problem areas originally defined for the Programme. Other achievements were appraised in terms of:

- Programme development: improvements in definition, scheduling, scope, and participation in resource programmes.

- Scientific communication and exchange: improvements in contacts, publication, and transfer of scientific know-how.

\section{SIGNIFICANT SCIENTIFIC ACHIEVEMENTS}

\section{Improved techniques, methods, and standards}

Effective geological research depends on the adequacy of the techniques and methods available to the geologist, and the use of standards of terminology and methodology to achieve results that are predictable, reliable, and comparable with work done elsewhere. These are tools of research, and because they are so important to the success of IGCP, the Board has accepted a number of projects specifically intended to improve these tools.

Of high priority are projects that deal with improved methods of establishing the time-equivalence and age of geological events and of rock units that record these events - in other words, better methods of geological time determination. Geologists need accurate time-determination methods for identifying and assessing energy and mineral resources. An understanding of the natural processes which have led to the accumulation of mineral deposits or fossil fuels depends on the geologist's ability to understand the sequence of stages responsible for the formation of any deposit, and to make accurate correlations between sequences concerned with the formation of similar deposits in widely separated regions.

One well-established method of determining the relative ages of rocks depends on the effects of organic evolution, in that the fossils contained in a rock represent samples of the plant and animal species that were alive at the time of deposition. Others involve comparing results of biostratigraphical studies with those obtained by techniques which date rocks by reference either to the breakdown of radioactive elements or to the succession of changes in the earth's magnetic field.

The first project accepted by the Board (Project 1 , Accuracy in time) was designed to test the precision of techniques used for the correlation of layered sedimentary rocks. A pilot study of micro-fossils contained in a sequence of Pliocene marine sediments in Sicily, deposited over a period of about a quarter of a million years, revealed inadequacies in existing methods of statistical treatment, as well as discrepancies in the identification of species by different experts. Current studies are concerned with the testing of numerical ways of defining subtle morphological variations among fossils and with extending the use of computer-based anlaysis of faunal data. This work, and that of several other projects, benefits from the fact that the International Programme of Ocean Drilling (IPOD) has made possible comparisons between the faunal sequences in deepsea sediments and those of the better-known sediments of the continental shelves.

Records of repeated reversals in the polarity of the earth's magnetic field are built into many sedimentary successions at the time of deposition and may provide fingerprints by which correlation of widely separated successions can be achieved. The primary magnetic orientations of interest for this purpose have, however, been obscured in many places by the effects of mineralogical changes during burial of the sediments.

Project 128 (Late Cenozoic magnetostratigraphy) is concerned with improving the technical means of separating these late effects from the initial magnetic record, in the framework of a study of reversals of polarity over the past few million years. Agreement has been reached on many aspects of correlation of continental sediments deposited over this period - a matter of crucial importance for research on the early evolution of the human race, because most hominid fossils are contained in such sediments.

Methods which involve measurement of the ratios between radioactive elements and the isotopes produced by their breakdown are capable of dating rocks in terms of millions of years. Such methods have until recently been difficult to apply to sedimentary rocks. Projects $133 / 89$ (Calibration of stratigraphic methods), which involve 51 laboratories in 20 countries, are devoted to improving the reproducibility of results. At the same time, studies of the ways in which chemical changes after deposition affect the dates given by minerals such as glacuonite have made possible a more accurate evaluation of the results.

Knowledge of the chemical compositions of rocks and of the variations within related rock suites is critical to the understanding of processes by which these rocks and their associated ores were formed. A vast reserve of analytical data has accumulated over the years, but because these data have been obtained by different methods and recorded according to different systems, they are not freely interchangeable. The development of internationally agreed 
conventions concerning the storage of analytical information in data banks is urgently needed to make it possible to use the data reliably in geological research.

Project 163 aims to design a world data base for igneous rocks which, once established, would be a permanent asset to the geological community. Projects 26 and 154 are approaching the problem of handling analytical data within the framework of specific studies of petrogenesis. Certain families of felsic igneous rocks are commonly associated with deposits of tin, tungsten, molybdenum, and other metals. The compilation of existing analytical data from many sources has established the patterns of variation within these rock families and led to the formulation of geochemical criteria by which the complexes most likely to be mineralized may be recognized. This approach has considerable potential for mineral exploration.

Computerized data banks are powerful tools for resource inventory and assessment, modelling and exploration of deposits, evaluation of ore bodies, and other areas of geological research. To perfect and broaden their application in resource studies is the objective of Project 98 . A conference was held to review data-base standards and a data standards document is now being prepared for publication and use in establishing data bases for mineral resources. The project is also concerned with the development and documentation of a method for integrating geological, geochemical, geophysical, and remote-sensing data, together with subjective probability estimates. This work is being carried out in conjunction with the IUGS Committee on Storage, Automatic Processing and Retrieval of Geological Data (COGEODATA) to ensure that all data standards and computer applications are fully coordinated internationally. The project is scheduling resource inventory and assessment studies in selected developing countries to demonstrate computer applications, along with a series of workshops on computer application techniques in Latin America, East Asia, and Africa.
Better knowledge of geological processes, correlations, and concepts.

The Board has given priority to projects dealing with the more significant episodes in the evolution of the earth's crust, with special emphasis on Precambrian rocks - the ancient crust. These are important, partly because they contain most of the world's major iron ore deposits as well as nickel, chromium, gold, and uranium, and partly because they generally lack fossils or are metamorphosed, and therefore require the combined efforts of petrographic, isotopic, paleomagnetic, and other specialists for correlation. Nine projects pertain to these problems and a further three to mineral deposits found in Precambrian rocks.

The oldest rocks available for study are the subject of Projects 92 (Archean geochemistry) and 160 (Early exogenic processes) concerned respectively with the evolution of the early continents and with the processes acting at the surface of the early earth; the rocks under investigation are more than 2,500 million years old. The intrinsic scientific interest of their study lies in the possibility that conditions at and beneath the earth's surface during this early period were substantially different from those which prevail today. Progress has been made in defining the studies needed for genetic interpretations of Archean strata and in mobilizing specialists in geochemistry, mineralogy, petrology, geochronology, and structural geology for the studies.

The difficulties of correlation in Precambrian rocks have delayed the identification of regional or worldwide geological events dating from the Precambrian Era. With the improvement of techniques of age-determination, the time is now ripe for international advances in this field. IGCP has made it possible for problems to be tackled at the requisite scale: participants in Projects 2 and 22 have assembled provisional correlation tables for successions in the scat tered Precambrian complexes of North America, southern Europe, and western Asia - regions in which many groups using different languages formerly worked in isolation.

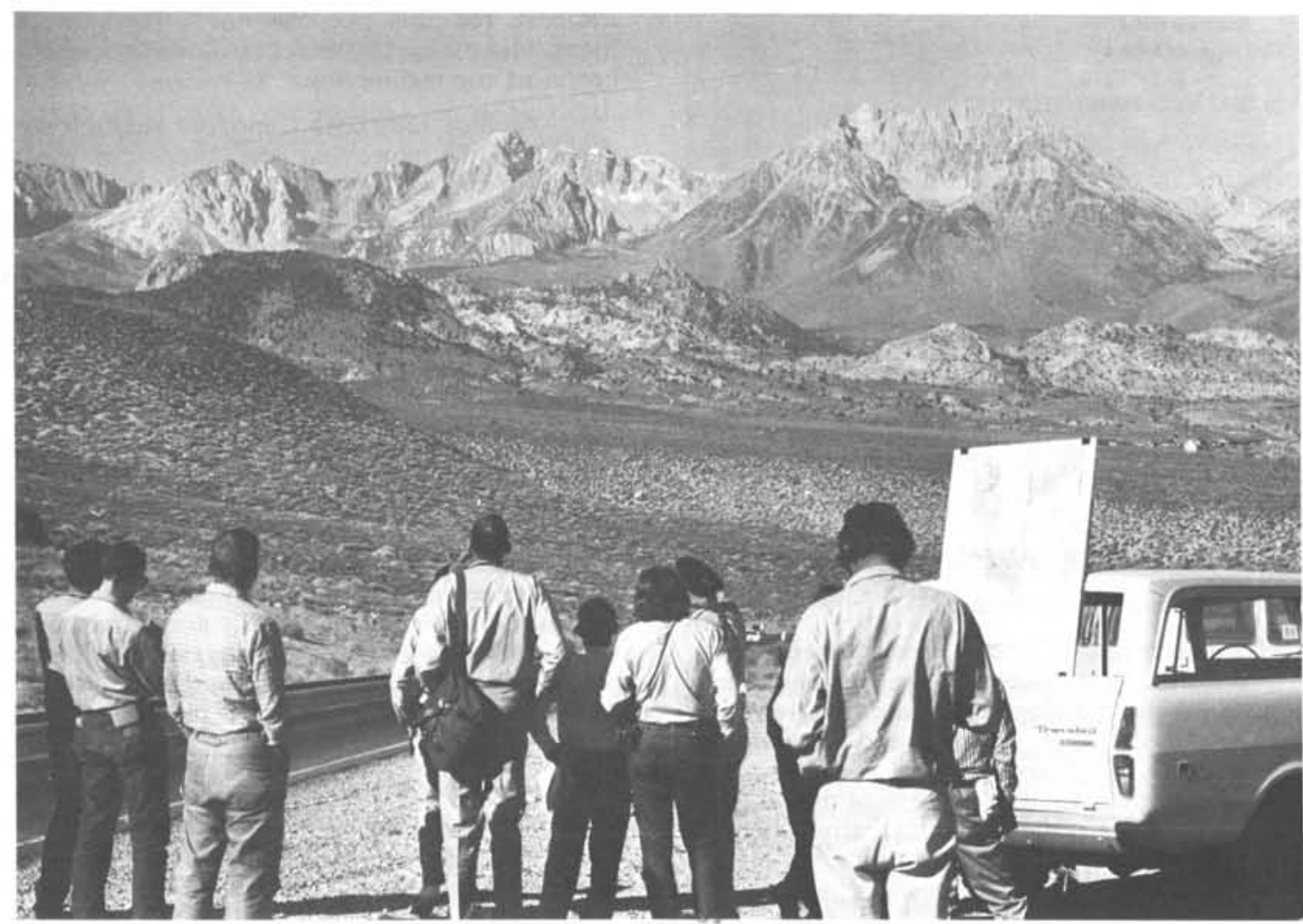

An IGCP working group receives a briefing on the regional geology of an area in western U.S.A. before starting a day of studying specific, key field relationships. 
Projects 118 and 29 focus on the correlation of the late Precambrian and the definition of the Precambrian/Cambrian boundary. This time-period of severe ice ages is of exceptional interest as it was a turning point in organic evolution marked by the appearance of the first shelled animals. It was a period in which large deposits of phosphates (subject of Project 156) were laid down. Understanding of these varied phenomena depends on the establishment of a secure stratigraphical framework for correlation. Agreement on many aspects of this framework, notably on the criteria to be used in defining the base of the Cambrian, has been reached during field and discussion sessions.

Several projects contribute to the understanding of geological processes that operate on a worldwide scale or of very large geological features, such as the belt marked by exceptional volcanic and seismic activity that encircles the Pacific Ocean. Project 30 (Circum-Pacific plutonism) is undertaking the first comparative study of the granite batholiths within this belt. Joint field investigations by experts from many countries have facilitated the recognition of variations in the characteristics of these granites, which can be interpreted in terms of variations in structure of the continental margin and in depth of erosion. Systematic changes have been identified in the chemistry of the intrusives away from continental margins in North America and Australia, that do not seem to apply in Asia. Patterns of deformation and compositional zoning have been established, and it is believed that mineralization related to these batholiths is largely a result of remobilization of metals from surrounding rocks.

Another major problem of correlation and genetic concept is being studied by Project 39 (Ophiolites), concerned with those assemblages of ultramafic and related igneous rocks believed to have accumulated on the ocean floor and which have been detached from their roots during profound structural disturbances. In some places these rocks carry concentrations of nickel, copper, or chromium. Significant advances in understanding depend on knowledge both of the oceanic environment in which the ophiolites originate and of the processes by which they are displaced. A cruise of the USSR research vessel Dmitri Mendeleev in the western Pacific in 1976, during which new surveys of arc and trench environments were completed, provided valuable data on the early stages of ophiolite formation.

A comparable effort is Project 27 (Caledonian orogeny) studying crustal evolution during the first part of the Paleozoic Era. This project is coordinating research on both sides of the Atlantic Basin to develop a better understanding of the sequence and correlation of geological events prior to the opening of the Atlantic; it is associated with ore deposits being studied in Project 60. A plan for compiling and issuing standardized maps at a scale of 1:1 million has been developed, reference files of materials in participating countries have been established, and a review volume on the status of Caledonian geology is underway.

Many of the sedimentary basins from which minerals, coal, or oil may be obtained are very large structures, some extending beyond the borders of a single country. The connected sedimentary basins that flank the western Pacific and extend westward through Asia are of this kind. Project 32 (Stratigraphic correlations between sedimentary basins in the ESCAP region), planned in association with the United Nations Economic and Social Commission for Asia and the Pacific, aims to compile an atlas containing a geological base map and a series of stratigraphical columns summarizing the geological features of each basin. Preliminary editions of 5 of the 13 base-map sheets and of the atlas contributions of Malaysia have already been published. Together with the results of several related projects $(7,8,2 ;, 41$, and 114$)$, this project will provide a comprehensive summary of information essential for the assessment of energy resources in the ESCAP region.
Project 41 (Stratigraphic correlation between the Tethys and Paratethys Neogene) is studying geological events and stratigraphical correlations along the mountain systems from the Mediterranean through the Himalayan region and into the ESCAP area. Interpretations of palaeogeological conditions along this belt early in the Cenozoic Era will have significance for petroleum and mineral exploration in Asia.

The correlation of strata within the great sedimentary basins of South America calls for studies on a comparable scale. Project 42 is designed to advance understanding of the Upper Palaeozoic strata that underlie little-known regions in the Amazon and Parana basins and in the Andean foothills. Formulation of the project has already led to a rationalization of the deployment of manpower and to coordination of the effort given to this vast problem. A better correlation within and between basins has thrown new light on the effects of Paleozoic ice ages and has provided the basis for better appreciation of the distribution of fossil flora and of the resources of coal, oil shale, radioactive minerals, and other raw materials in these rocks. As an adjunct of this project, comparative studies of geologically equivalent basins in Africa are being coordinated with the South American studies.

Finally, the Mediterranean Sea and the lands along its borders are the focus of many regional projects (eg., 4, 5, 25, 96,105 ). Among these, Project 96 (Messinian correlation) deals with the evidence for a truly remarkable event only recently recognized by earth-scientists - the almost complete dryingout of the Mediterranean basin and the precipitation of salts on the sea floor in Miocene times. The geological consequences of this event for problems connected with the quality of groundwater and the origin of phosphates in North America are only now coming to light.

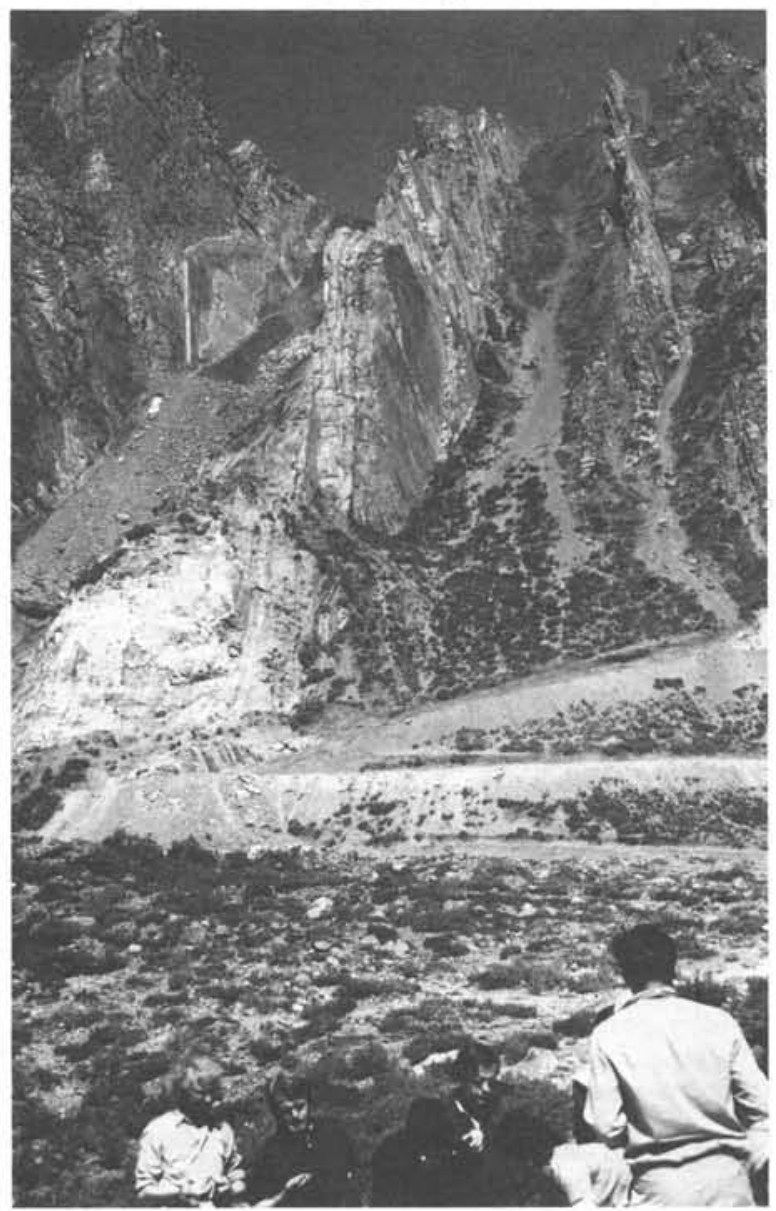

Participants of an IGCP working group studying upended Cretaceous strata in Chile. 


\section{More effective protection and utilization of the environment}

The geological environment within which mankind lives has been shaped very largely by the events of the past few hundred thousand years. The Quaternary Period, or the latest unit of geological time, was one of dramatic climatic variations which led to the repeated advance and retreat of enormous ice sheets and to consequent changes in sea level, in the activity of river systems, and in the natural vegetation. Our hope of anticipating the effects of future climatic fluctuations lies, in part, in an understanding of the record of the past. Furthermore, sedimentary deposits of Quaternary age are important sources of water supplies and building materials, and provide foundations for many cities and great engineering works.

Because the time-span of the Quaternary was small, precision in the correlation of events is of prime importance, and several projects are designed to strengthen the stratigraphical framework within which the history of climatic change must be assessed. The definition of the lower boundary of the Quaternary is the objective of Project 41. Key areas in Japan, Spain, France, and Italy have already been examined and agreement has been reached on the choice of a stratotype section. The time boundary identified in this section can now be recognized in continental and ocean-floor sediments of both northern and southern hemispheres. Rapid advances have been made, largely because experts could be brought together in field sessions to assess and discuss the evidence.

Direct records of the advance and retreat of ice-sheets are provided by the sculpturing of landscapes, by modifications of river and lake systems, and by sediments of glacial origin. When these diverse records can be correlated on a global scale, a detailed picture of climatic fluctuations over tens of thousands of years will emerge. Project 24 (Quaternary glaciations of the northern hemisphere) is concerned with clarifying this picture. Progress has been made on the basis of correlation between records of the northern ice-sheet of Europe and the Alpine ice-cap; the next stage of the project will extend correlation to the records of North America. The variations of sea level which accompanied the waxing and waning of ice sheets are the subject of Project 61 . A depth-time curve constructed on the basis of studies along the eastern coast of U.S.A. and an atlas of sea-level curves are examples of the approach adopted for this problem.

The climatic variations of the Quaternary Period were felt from the poles to the equatorial regions. In low latitudes, they were expressed by variations in rainfall and by consequent migrations of the boundaries of arid regions. These changes are recorded by the sediments of flood plains, lake-beds and river systems that form the subject of Project 146. In Mesopotamia and Greece, the younger (Holocene) sediments contain archaeological remains which record the successive phases of human occupation. Integration of the geological and archaeological records has illuminated the history of climatic fluctuations during the development of Stone-age, Bronze-age, and Iron-age cultures. Project 158 (Palaeohydrology of the temperate $z$ one) focusses on changes in groundwater conditions over this period of time, with the objective of identifying fluctuations related on the one hand to climatic variations and on the other to the impact of human activities.

These studies provide the basic knowledge on which planned development and conservation of water resources in semi-arid regions must depend, and may prove to be of value in understanding the spread of desert conditions and in initiating measures to minimize the effects of desert encroachment.

In tropical and subtropical climates, rocks exposed at the surface are profoundly modified by weathering, with the production of laterites and bauxites, some of which carry residual concentrations of aluminum, nickel, chromium, and other metals. In Project 129 (Laterization processes) preliminary studies have been within the Indian subcontinent, but the work is being broadened to include studies in other tropical areas in cooperation with the Working Group on Laterites of the International Association for Geochemistry and Cosmochemistry. Project 127 (Revision of the continental terminal concept in Africa) is concerned with the reassessment of the weathered materials mantling large areas in Africa, which have hitherto been grouped together, but which now appear to be of many different ages and origins. This project draws support from ten countries in west and central Africa.

\section{More efficient identification and assessment of resources}

Many, if not most, of the IGCP projects contribute substantially to more efficient identification of energy, mineral, and water resources. Five projects are concerned with regional aspects of mineralization. Because, as noted earlier, the Precambrian geological environments differed in some respects from those which can be observed today, Precambrian mineral deposits are of special interest. Project 132 (Basins of iron formation deposition) deals with the huge Proterozoic banded iron formations which are among the principal sources of high grade iron ore. The conditions of formation of these enigmatic rocks are still far from clear and the objective of the project is to compare the principal outcrops in Western Australia, southern Africa, Brazil, U.S.S.R., nor thern United States, and Labrador, in order to identify features common to all. An important development lies in the use of palaeomagnetic techniques to determine whether or not deposition was restricted to certain climatic zones.

Project 91 (Metallogeny of the Precambrian) is designed to approach the problems of ore distribution by studying key regions such as the Baltic and Ukranian shields in Europe, the Guyana Shield in South America, and the Precambrian areas of southern Siberia and Western Australia. Themes of special significance include the role of organic material in the formation of Precambrian ores and the relationship between Precambrian styles of magmatism and of mineralization. The distribution of Precambrian and younger ore deposits defines a number of provinces characterized by unusual concentrations of certain metals, and the recognition of such provinces helps to guide mineral exploration.

Many mineral provinces formed early in the history of the earth have been partially destroyed by later structural disturbances or have been broken up by the opening of new oceans within their boundaries. Project 3 (Ore provinces separated by continental drift) arises from the inference that metallogenic provinces on one side of such an ocean may match those on the other. It is generally agreed that South America and Africa were formerly united in a single supercontinent. New compilations of the distribution of diamonds and of copper, lead-zinc, and tin ores reveals an impressive continuity from western Africa into eastern South America and provides a stimulus for mineral exploration in little-known regions on both sides of the Atlantic.

An example of a widely distributed but genetically related suite of minerals is provided by the tin, tungsten, and molybdenum ores formed in association with silic intrusive and volcanic rocks - the theme of Project 26 (Mineralization associated with acid magmatism). A second example, being studied by Project 60 (Caledonian stratabound sulphides), is provided by the copper and zinc sulphide ores associated with volcanic or sedimentary rocks in the Caledonian fold belt that traverses western Scandinavia, Britain, east Greenland, and eastern North America. A number of new areas of mineralization have already been located and detailed chemical and structural investigation of well-known deposits such as the copper ores of Norway, have revealed new features which will assist further exploration.

Five projects deal with individual types of deposits of worldwide importance - base metals in carbonate host rocks (6), kaolin (23), manganese ores (111), phosphorites (156) and sulphide ores in mafic and ultramafic hosts (161). Forty 
countries concerned with kaolin production are represented in the working group which coordinates new data such as that provided by scanning electron-microscope studies. The outlines of a genetic classification have been worked out and criteria for prospecting for new deposits have been established.

Manganese ores are also formed by a variety of processes, and deposits of different types have hitherto been studied mainly in isolation. Project 111 promotes a multidisciplinary approach to establishing the distinctive features of different types of deposit. Current interest in the economic potential of manganese nodules found on the sea floor is reflected in the emphasis given to marine research. The factors which control the distribution of manganese nodules and the variations in their contents of iron, nickel, and other metals are not yet well known; future work will be directed to establishing the roles of submarine volcanicity on the one hand and of reactions between sea-floor sediments and sea waters on the other.

Although no projects devoted solely to energy resources have been established, many dealing with the development of sedimentary basins and the correlation of strata within and between basins have a bearing on the distribution of oil, gas, or coal. Among these, Project 32 is of particular interest to countries of the ESCAP region. Project 53 (Ecostratigraphy) seeks to promote an integrated and wide-ranging approach to basin analysis in general, and the recently accepted Project 157 (Early organic evolution and mineral and energy resources) to investigate the characteristics of Lower Paleozoic and Proterozoic basins as potential sources of oil. Project 115 (Siliceous deposits of the Pacific region) is organizing research on the correlation, origin, and evolution of the siliceous deposits commonly associated with hydrocarbons, iron, manganese, and phosphate deposits.

The rapidly developing field of remote sensing is the theme of Project 143. Analysis of Landsat images has already revealed relationships between visible lineament patterns and the siting of mineral deposits, and recent technical advances are widening the scope of exploration techniques. The need for agreement on descriptive terminology and classification of phenomena in this new field can be met within the framework of the project by exchange of information and views.

\section{Scientific Impact: Summary}

IGCP has had its greatest scientific impact in the following ways:

1. It has focussed attention on geological phenomena developed on a continent-wide or a worldwide scale.

Projects concerned with regional correlation and with the standardization of terminology and data presentation have provided an important stimulus to the resolution of technical problems which stand in the way of a global approach to the understanding of the structure and history of the earth.

2. It has encouraged scientists to match the scale of their enquiries to that of the phenomena under investigation.

Existing programmes of geological reconnaissance have been extended or made more effective by the interchange of information and personnel. The participation of specialist groups with access to scarce and expensive facilities has made possible an interdisciplinary approach which has speeded up advances in the field of correlation.

3. IGCP interim scientific results can be brought to bear on the search for natural resources and on questions concerned with the geological environment.

4. It has greatly encouraged the use of standards and techniques for data handling, computer applications, reporting, and other operations needed for productive, efficient, and reliable research projects in most participating countries.

\section{SCIENTIFIC PROGRAMME DEVELOPMENT}

IGCP has also had notable success in strengthening and developing geological research and resource programmes, especially in and with the developing countries.

\section{Extension and broadening of research}

Many projects are outgrowths of research in a limited area, or of uncoordinated activity in several areas. One significant example, still in the process of growth, is Project 132, wherein research on iron-formation in the Hamersley Basin in Western Australia is now being extended into a coordinated research effort in at least 7 major iron-formation areas in 5 continents. This will more likely succeed in resolving problems of the origin, significance, and extent of iron-formation.

Another important example is Project 39, in which scattered studies of ophiolites have been integrated and systematized in a worldwide study. This project may have far-reaching consequences in the search for chromium, nickel, platinum, and other raw materials commonly associated with such sequences. The coordination of research on plutonic rocks around the margin of the Pacific Basin through Project 30, which has held field study and consultation seminars in 11 countries bordering the Pacific, and the consolidation of research on the Caledonian orogen between Europe, North America, South America, and Africa through Project 27, serve as similar examples.

\section{Greater involvement of scientists in programme development}

The coordination of research through IGCP has been accompanied by a substantial increase not only in the number of geologists involved in research, but also in their participating in the definition, planning, and organization of major research projects. For example, in September 1975, long-range plans for research on Precambrian geology were developed at a meeting organized by the USSR National Committee for IGCP, in which members of 8 IGCP projects participated. IGCP has subsequently stimulated project planning for research on Quaternary geology through a meeting in Japan, and Precambrian geology in West Africa through a meeting in Togo, as well as a number of other regional meetings for planning projects mainly in Asia and Africa. In addition, many geologists have become involved with planning, justifying, and organizing IGCP research projects through participation in project working groups, of which several hundred meetings have now been held.

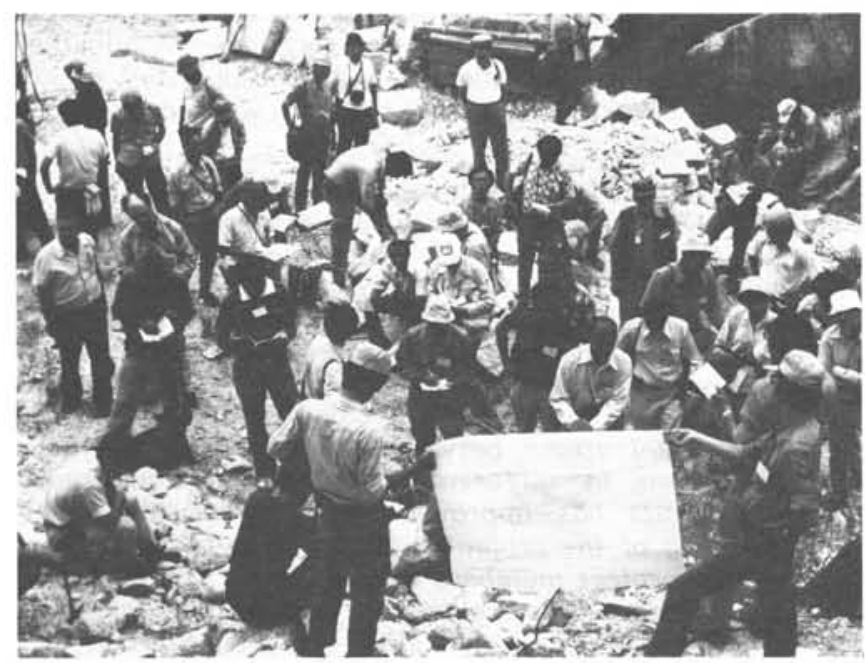

A small working group meeting of an IGCP project in Japan led to the involvement of approximately 100 geologists from the region. 


\section{Support for other international programmes}

As IGCP evolves, it will make an increasingly valuable contribution to other international resource and environmental programmes such as the United Nations Revolving Fund for Resources Exploration (UNRF) and the International Atomic Energy Agency (IAEA), which need geological information and exploration targets on which to base their activities. Some of the IGCP projects, such as Project 111 (Genesis of manganese ore deposits), and Project 156 (Phosphorites of the Proterozoic-Cambrian), can form the basis for identifying new deposits or possibilities that might be considered for exploration or development under UNDP or UNRF. Similarly, projects such as 61 (Sea-level changes) and 146 (River flood and lake-level changes) can provide information about man's environment that is important for the United Nations Environmental Programme (UNEP).

As mentioned earlier, IGCP makes use of information provided by other programmes. For example, Project 128 uses data from the Deep Sea Drilling Programme (DSDP), along with continental data, in attempting to establish a global chronostratigraphical framework. Project 158 both contributes to and utilizes data from the International Hydrological Programme (IHP), as do several other projects with the Circum-Pacific Map Project. Project 32 provides substantial input to ESCAP in the correlation and analysis of sedimentary basins.

\section{COMMUNICATION AND EXCHANGE}

\section{Better exchange of information, methods, and technology}

Perhaps the most valuable achievement of IGCP during its early years has been the increased communication among earth scientists, and the consequent increased effectiveness with which these scientists are able to contribute to research and development programmes in their respective countries. Benefits include better exchange of information and methods, wider contacts between scientists in different parts of the world, increased publication by and recognition of earth scientists in developing countries, and transfer of technical and scientific know-how to developing countries.

Some projects have been notably successful in exchanging information through periodic symposia: for example, Project 23 has greatly stimulated and systematized worldwide research on kaolin through this way. Other projects rely on comprehensive periodic newsletters to promote communication: for example, Project 58, dealing with correlation of events during mid-Cretaceous time, and Project 143, on the application of remote sensing in mineral exploration, regularly issue newsletters to inform participating scientists of the progress of research under the project, as well as new concepts or techniques applicable to the research. Project 156, dealing with phosphorites, recently issued its first newsletter to 120 research workers throughout the world.

Wider contacts and exchange of information have developed more productive and cost-effective research. Project 8, for example, dealing with Mesozoic correlations in the New Zealand-New Caledonian region, has led to a major revision in the paleogeographical history of the region, which may affect exploration for resources. The leader of Project 30 has identified the benefits from improved communications as follows:

"Communications between geoscientists studying plutonism in different countries and different continents has improved vastly since the first meeting of the project in 1972. Prior to 1972, few of the project members were aware of the identity of fellow workers elsewhere around the Pacific. The project has now held field excursions in 11 countries representing all the larger land masses bordering the Pacific, and an estimated 500 scientists have participated in at least one project meeting or field trip. Because of project activities, geoscientists concerned with plutonism are now known to one another not just as names, but as individuals. Increased exchange of data, concepts, and services has resulted."

\section{Increased publication}

Increased communication has been reflected in, and achieved in part by, increased publication of scientific papers. This is especially important in developing countries which need to have more published geological information to encourage exploration and development of resources. Although several hundred papers have already been published as a direct result of IGCP work, they are not a valid indication of the ultimate productivity of the Programme, since most projects will not be completed for several years. Map series that will be issued toward the end of several projects will break new ground in recording not only new data but also classes of information not systematically presented elsewhere. IGCP map series can provide uniform coverage regardless of national frontiers; for example, maps compiled by Project 86 incorporate contributions from 10 European countries.

\section{Transfer of technical and scientific know-how}

Although IGCP is not intended to be a technical assistance programme, nearly all projects involve the participation of developing-country scientists who have the opportunity, through project working group meetings, field seminars, newsletters, and correspondence with developedcountry participants, to acquire new techniques, concepts and research results. Project 98, dealing with standards for computer applications in resource studies, illustrates this well. Such standardized procedures are necessary not only for valid national economic projections but also for efficient and well-coordinated international research of predictable quality. The project is attempting to achieve its goals through periodic conferences, newsletters, and selected demonstration activities. Its most recent conference, held in Nairobi during November 1977, had 43 participants from 24 countries, including 10 developing countries, and involved actual work with resource problems and models in 7 workshops during the conference.

Many other IGCP projects are especially effective channels for developing country access to new technology: Project 128, involving the use of rock magnetism in stratigraphical correlation; Project 143, which uses remote sensing in mineral exploration; Project 148, dealing with the development and use of quantitative techniques in stratigraphical correlation; Project 154, which considers a global exchange of data and standardization in geochemistry; and Project 163, dealing with the development of a world data base for igneous petrology.

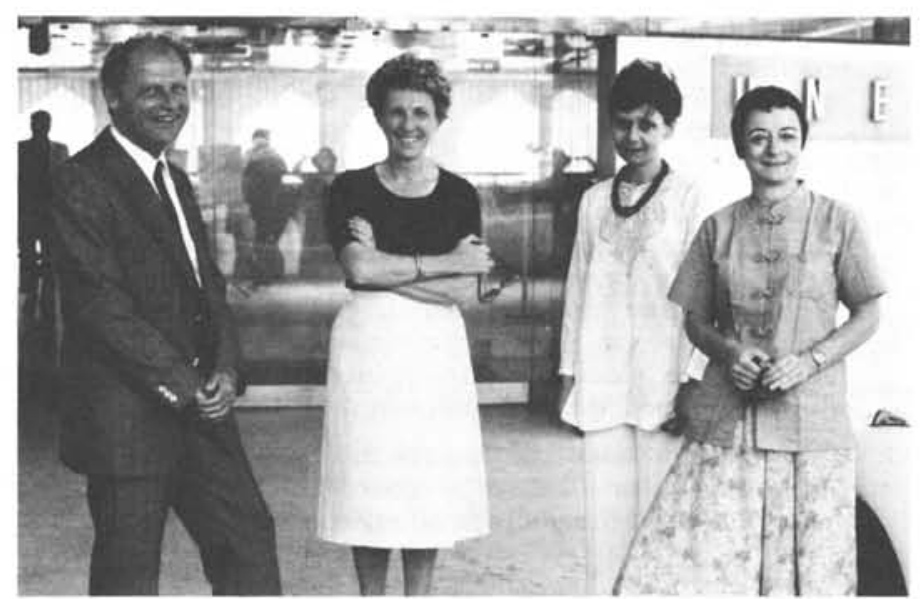

Members of the IGCP Secretariat in Paris, left to right: Dr. E. von Braun (Secretary, IGCP), Mme. C. Espinasse, Mlle. A. Bugnon, Mme. L. d'Andigné de Asis (Program Officer). Missing: K. Kitizawa. 


\section{FUTURE DEVELOPMENT}

Clearly, the scope and direction of IGCP development is not designed to cover the entire field over which the earth sciences impinge on human needs. The unifying theme of geological correlation has, from the first, focussed attention on problems concerning the relationships of rock bodies in time and space - a theme which is at once fundamental to the understanding of our geological environment and most appropriately followed up by international endeavour. With the preliminary stages of formulating projects, establishing channels of communication, and organizing the collection of data now largely completed, the Programme is moving into a new phase.

During this phase, which will see the emergence of results from many projects, further scientific developments will be influenced by two principal considerations: the need for intensified research on fundamental problems applicable to economic and social advancement, and the need to broaden the participation of scientists in developing countries.

\section{Geological applications to economic and social development}

The history of IGCP to date, and the joint sponsorship of UNESCO and IUGS, have ensured the scientific validity of the studies that have been undertaken. The wholehearted participation of geologists from universities, research institutions, and official organizations shows that the Programme has caught the imagination of the international scientific community. Many projects are already dealing with problems at the interface between basic science and applied science and it seems clear that this is the area in which the Programme can make its greatest contribution.

The understanding of geological phenomena developed on a regional or worldwide scale is the key to the solution of many questions concerning the distribution of mineral resources and fossil fuels. Such an understanding, however, cannot be achieved without in-depth studies which may be beyond the scope of individual geological surveys or institutes burdened with urgent day-to-day tasks. Provided that the Programme retains the confidence of its participants and its sponsors, IGCP should be able to make a substantial impact in this area.

\section{Broadening developing-country participation}

Working meetings held in developing countries or attended by representatives of such countries are effective means of assisting in the transfer of know-how because they bring scientists experienced in diverse fields into contact with groups working in isolation. Field sessions allow the expertise of such scientists to be brought to bear directly on problems of interest to developing countries. Cooperation along these lines is only now becoming effective. The Board has resolved to encourage such cooperation by the allocation of extra funds, so far as resources permit.

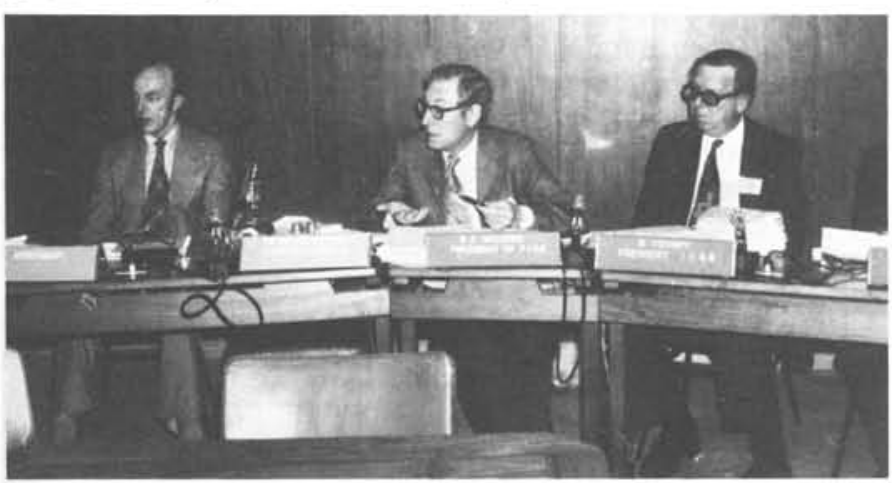

Dr. D.J. McLaren, Chairman of the Board, directs a discussion during the sixth meeting of the IGCP Board in Paris, February, 1978. Left to right: E.M. Fournier d'Albe (exofficio member of the Board representing UNESCO), D.J. McLaren, R. Trümpy, (President, IUGS).

\section{CONCLUSION}

The extent to which IGCP has attracted the support of scientists funded by governments, national research councils, academies, and universities around the world shows that the Programme is widely seen to be productive. The resources of manpower and equipment on which these workers draw collectively represent a massive investment in earth science.

The budget of IGCP itself is no more than a small fraction of this investment. It is needed for two principal purposes: firstly, to promote the effective organization of the Programme and ensure its scientific relevance; and, secondly, to support the project working meetings at which the most fruitful exchanges of information take place and which assist scientists from developing countries. Provision for these purposes is essential if IGCP projects are to continue their effective role as focal points at which the experience and resources of earth scientists are brought to bear on subjects of importance to all.

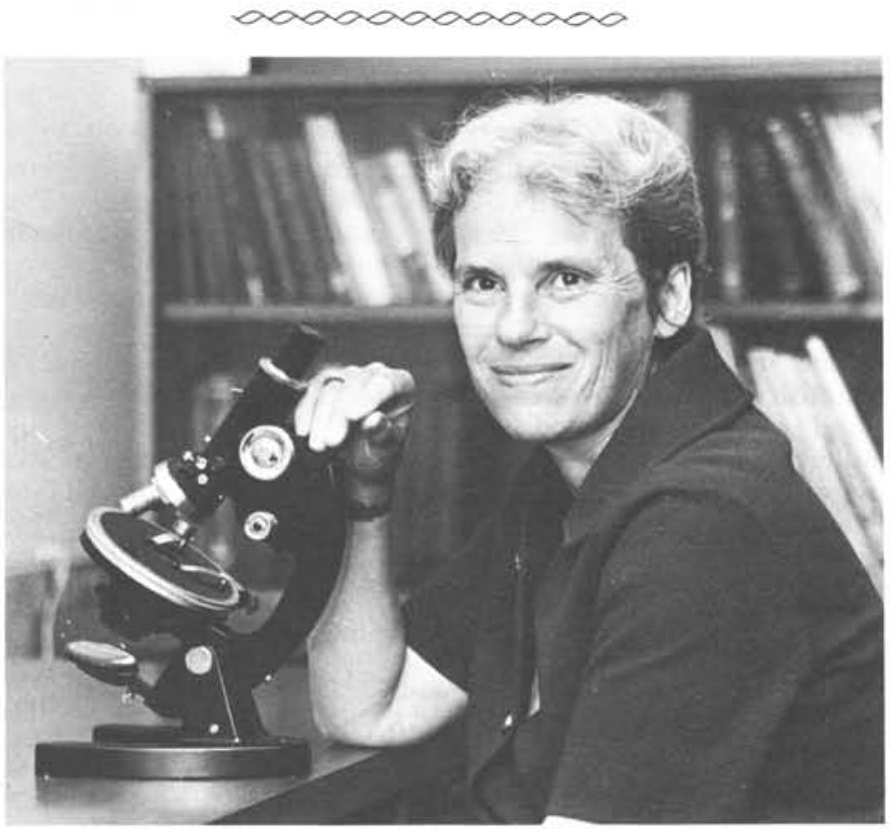

Professor Janet V. Watson

\section{ABOUT THE AUTHORS:}

Professor of Geology at Imperial College, University of London, U.K., Janet Watson has published numerous articles on the deformational and metamorphic history of the Moine, Dalradian and Lewisian schists and gneisses of Scotland. Since 1965 she has become increasingly more involved in the broader aspects of the study and evolution of the Precambrian in Scotland, North America and elsewhere, and more recently co-authored with H.H. Read the second volume of Introduction to Geology (1975). Her honorary distinctions include service as Vice President of the Geological Society of London from 1974 to 1976.

Dr. John A. Reinemund is the Chief of the Office of International Geology in the U.S. Geological Survey. A member of the Board since 1972, Dr. Reinemund will -become Treasurer of IUGS early in 1979 (see PEOPLE IN THE NEWS, p. 28). 